The INL is a

U.S. Department of Energy

National Laboratory

operated by

Battelle Energy Alliance

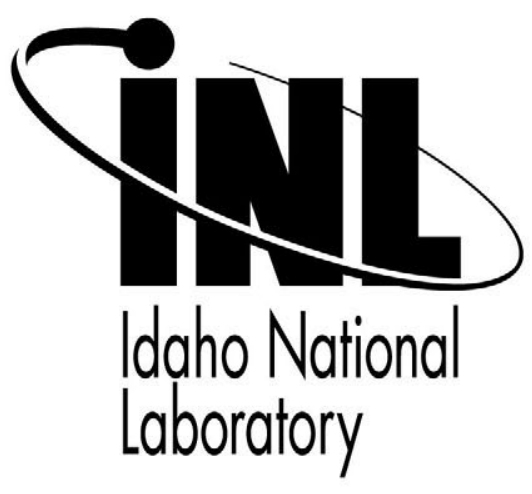

\title{
Detection of Shielded Nuclear Material in a Cargo Container
}

International Conference on Accelerator Applications 2005 (AccApp05)

J.L. Jones

D.R. Norman

K.J. Haskell

J.W. Sterbentz

W.Y. Yoon

S.M. Watson

J.T. Johnson

J.M. Zabriskie

B.D. Bennett

R.W. Watson

J. F. Harmon

\section{June 2005}

This is a preprint of a paper intended for publication in a journal or proceedings. Since changes may not be made before publication, this preprint should not be cited or reproduced without permission of the author. This document was prepared as an account of work sponsored by an agency of the United States Government. Neither the United States Government nor any agency thereof, or any of their employees, makes any warranty, expressed or implied, or assumes any legal liability or responsibility for any third party's use, or the results of such use, of any information, apparatus, product or process disclosed in this report, or represents that its use by such third party would not infringe privately owned rights. The views expressed in this paper are not necessarily those of the United States Government or the sponsoring agency. 


\title{
Detection of Shielded Nuclear Material in a Cargo Container*
}

\author{
J.L.Jones ${ }^{\mathrm{a}}$, D.R. Norman ${ }^{\mathrm{a}}$, K.J. Haskell, J.W. Sterbentz, W.Y. Yoon ${ }^{\mathrm{a}}$, S.M. Watson ${ }^{\mathrm{a}}$, \\ J.T. Johnson ${ }^{\mathrm{a}}$, J.M. Zabriskie ${ }^{\mathrm{a}}$, B.D. Bennett ${ }^{\mathrm{a}}$, R.W. Watson ${ }^{\mathrm{a}}$, J.F. Harmon ${ }^{\mathrm{b}}$ \\ ${ }^{a}$ Idaho National Laboratory, P.O. Box 1625, MS 2802, Idaho Falls, Idaho, 82415-2802 \\ ${ }^{b}$ Idaho State University, 1500 Alvin Ricken Dr., Pocatello, Idaho 83201
}

Elsevier use only: Received date here; revised date here; accepted date here

\begin{abstract}
The Idaho National Laboratory, along with Los Alamos National Laboratory and the Idaho State University's Idaho Accelerator Center, are developing electron accelerator-based, photonuclear inspection technologies for the detection of shielded nuclear material within air-, rail-, and especially, maritime-cargo transportation containers. This paper describes a developing prototypical cargo container inspection system utilizing the Pulsed Photonuclear Assessment (PPA) technology, incorporates interchangeable, well-defined, contraband shielding structures (i.e., "calibration" pallets) providing realistic detection data for induced radiation signatures from smuggled nuclear material, and provides various shielded nuclear material detection results. Using a 4.8-kg quantity of depleted uranium, neutron and gamma-ray detection responses are presented for well-defined shielded and unshielded configurations evaluated in a selected cargo container inspection configuration. (C) 2001 Elsevier Science. All rights reserved
\end{abstract}

\footnotetext{
* Corresponding author. Tel.: 208-526-1730; fax: 208-526-5208; e-mail: james.jones@inl.gov (Supported in part by the Department of Homeland Security under DOE Contract No. DE-AC07-05ID14517.)
} 


\section{Introduction}

The Idaho National Laboratory (INL), along with Los Alamos National Laboratory (LANL) and Idaho State University's Idaho Accelerator Center (ISU/IAC), has been developing a high energy photon interrogation system for non-intrusive inspections of air-, rail-, and maritime cargo containers $[1,2]$. This energetic photon inspection technology is referred to as the Pulsed Photonuclear Assessment (PPA) technology and is supported by the Department of Homeland Security. The PPA technology development is addressing one of our homeland security's most important concerns terrorism associated with the transportation of weapons of mass destruction (WMD), specifically weapons employing nuclear materials, such as highly enriched uranium (HEU). While all aspects of cargo container transportation and security is important, the focus of this paper is with shielded nuclear material detection in maritime cargo containers (or trucks) since these represent the most common mode of commercial transportation. This paper briefly describes the prototype PPA inspection system and then presents detection results from a selected cargo container inspection configuration. The photonuclear-induced, radiation signatures are presented for a nominal $10-\mathrm{MeV}$ photon interrogation of a $4.8-\mathrm{kg}$ depleted uranium (DU) sample that is located within well-defined shielding configurations (i.e., INL "calibration" pallets) that are then positioned in the center of the inspected cargo container. This center-positioned DU, and/or the "calibration" pallet, provides relatively challenging detection scenarios because it results in the largest DU-to-detector distances.

\section{Inspection technology}

The PPA inspection technology uses pulsed, energetic photons to induce photofissions (and neutron-induced fissions) in shielded nuclear materials. The main features of the PPA inspection system include a pulsed electron accelerator (the photon source), a neutron and gamma-ray detection system [1,2], and an inexpensive gray scale mapping system for cargo loading characterizations [2]. Note, the PPA "mapping" component will not be discussed in this paper.

The pulsed photon source for the PPA prototype is the INL Varitron [3]. The Varitron is a mobile accelerator system capable of generating electron pulses of 2-12 MeV electrons at rates up to $1 \mathrm{kHz}$ with an on-board, electron beam current and energy monitoring capability. All signature emission data presented in this paper are provided with a nominal $10-\mathrm{MeV}, 125-\mathrm{Hz}$ operation producing about 3-4 $\mu \mathrm{A}$ (avg.) beam current.

The prototype neutron and gamma-ray detection system consists of a transportable stand consisting of an array of nine detector pairs at various elevations. Each collocated pair consist a neutron and gamma-ray detector. Figure 1 shows a detector assembly positioned along side a maritime-cargo container in a testing device at the IAC that provides container motion.

Neutron detection is accomplished with the patent-pending Photonuclear Neutron Detector (PND) design [1] that operates within intense pulsed, photon-flash environments and differentiates prompt and delayed fission neutrons emissions between every accelerator pulse. The unique PND design allows for the detection of 0.1 $\mathrm{keV}$ to $1.0-\mathrm{MeV}$ neutron since this energy range is representative of almost all delayed fission neutron emissions.

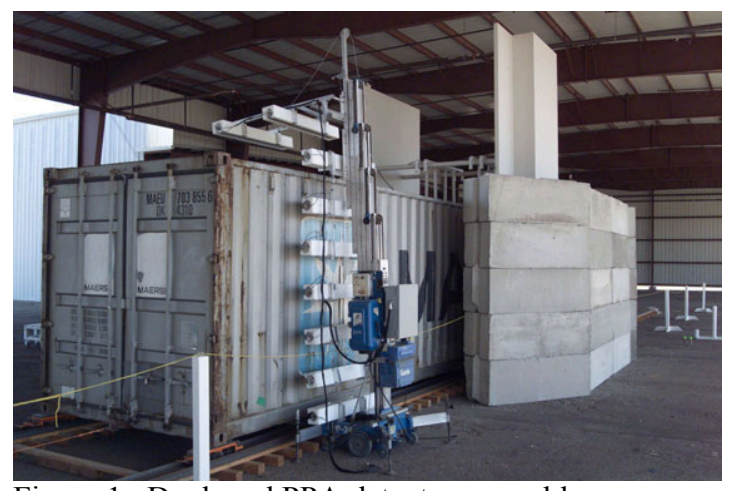

Figure 1. Deployed PPA detector assembly.

Gamma-ray detection is accomplished with the use of standard, 1.6-cm, 27.3-cm Geiger-Müller tubes (model LND 719) collocated with each PND. A figure-of-merit (FOM)-type parameter is used to 
characterize the induced-gamma-ray emissions.

This FOM is a ratio of the time-dependent responses of a GM tube and the thermal neutrons in a bare helium-3 tube.

\section{Inspection configuration}

The selected PPA inspection configuration for the maritime-cargo container assessment is shown in Figures 2 and 3. This configuration was selected to keep each detector assembly axis perpendicular to long axis of the cargo container and to allow an angular alignment between the accelerator beam axis and the detector assembly axis. For this inspection evaluation, an angle of about 42-degrees is selected with a $250-\mathrm{cm}$ standoff distance from the photon source to the center of the cargo container. As shown in Figure 3, the interrogating photon beam axis is $1.22-\mathrm{cm}$ from the ground level.

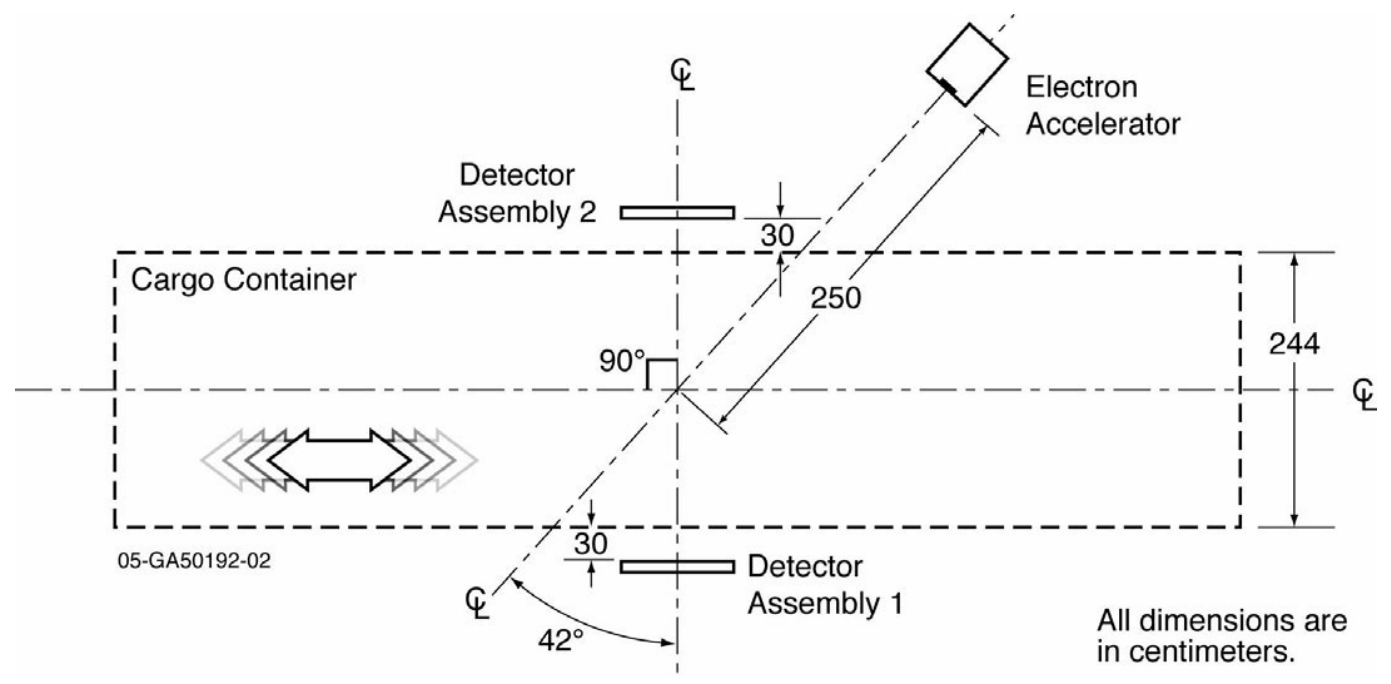

Figure 2. Top view of the cargo container inspection configuration.

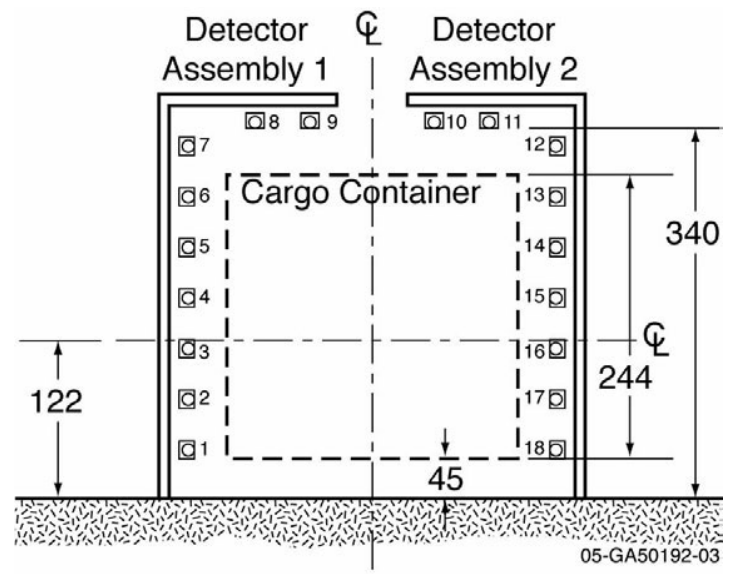

All dimensions are in centimeters.

Figure 3. End view of the cargo container inspection configuration. 


\section{4. "Calibration" Pallets}

To characterize the radiation shielding effects from a cargo container, a set of well-defined cargo loadings have been assembled [2]. This representative set of cargo loadings is referred to as the INL "Calibration" Pallets. Table 1 summarizes some key characteristics of these "Calibration" Pallet designs.

Table 1. Calibration Pallet Designs

\begin{tabular}{|l|c|c|c|}
\hline \multicolumn{1}{|c|}{ Pallets } & $\begin{array}{c}\text { Mass } \\
(\mathrm{kg})\end{array}$ & $\begin{array}{c}\text { Primary } \\
\text { Material }\end{array}$ & $\begin{array}{c}\text { Material } \\
\text { Density } \\
(\mathrm{g} / \mathrm{cc})\end{array}$ \\
\hline Empty & 46 & Aluminium & 2.70 \\
\hline Celotex & 90 & "Celotex" & 0.05 \\
\hline $\begin{array}{l}\text { Borated } \\
\text { Polyethylene }\end{array}$ & 1012 & $\begin{array}{c}5 \% \text {-Borated } \\
\text { polyethylene }\end{array}$ & 1.05 \\
\hline Polyethylene & 923 & Polyethylene & 0.95 \\
\hline Wood & 482 & Plywood & 0.48 \\
\hline Lead & 254 & Lead & 10.80 \\
\hline Iron & 890 & Iron & 7.80 \\
\hline
\end{tabular}

All pallet designs provide shielding completely around a centrally located nuclear material. The Wood, Celotex, Borated Polyethylene, and
Polyethylene Pallets are rectangular in shape and have a $1.07-\mathrm{m}$ depth, a $0.86-\mathrm{m}$ width, and a $1.02-\mathrm{m}$ height. The Lead and Iron Pallets are cylindrical in shape and have radial shield thickness of 5.08 and $20.32-\mathrm{cm}$, respectively. When the rectangularshaped pallets are placed within a cargo container, they are aligned with their long (depth) dimension parallel with the long container axis. This alignment allows a standard two-wide, two-high pallet loading in the cargo container.

\section{Results}

Tests were performed with (and without) a 4.8$\mathrm{kg}, \sim 14-\mathrm{cm}$ square DU sample in each of the INL "Calibration" Pallets located at the center of the cargo container configuration as indicated in Figures 2 and 3. All tests involved a 120-s data acquisition.

Table 2 presents the neutron detection response at detector positions \#3 and \#16 while Table 3 presents gamma-ray FOM parameter data from all gamma-ray detector positions. Shaded (or orange) table entries represent nuclear material detection based on the following threshold settings: 4E-14 neutron counts/e and a FOM=14.

Table 2. Selected neutron detection responses.

\begin{tabular}{|c|c|c|c|c|}
\hline \multirow[t]{3}{*}{ Pallets } & \multicolumn{4}{|c|}{ Neutron Counts/Electron (120 s inspection) } \\
\hline & \multicolumn{2}{|c|}{ Detector \#3 } & \multicolumn{2}{|c|}{ Detector \#16 } \\
\hline & No DU & With DU & No DU & With DU \\
\hline Empty & $2.30 \pm 0.29 \mathrm{E}-14$ & $9.97 \pm 0.19 \mathrm{E}-13$ & $2.31 \pm 0.29 \mathrm{E}-14$ & $5.62 \pm 0.14 \mathrm{E}-13$ \\
\hline Celotex & $1.88 \pm 0.26 \mathrm{E}-14$ & $9.11 \pm 0.18 \mathrm{E}-13$ & $2.46 \pm 0.28 \mathrm{E}-14$ & $8.44 \pm 0.17 \mathrm{E}-13$ \\
\hline $\begin{array}{l}\text { Borated } \\
\text { Polyethylene }\end{array}$ & $1.94 \pm 0.30 \mathrm{E}-14$ & $2.06 \pm 0.31 \mathrm{E}-14$ & $2.03 \pm 0.31 \mathrm{E}-14$ & $1.84 \pm 0.29 \mathrm{E}-14$ \\
\hline Polyethylene & $2.61 \pm 0.35 \mathrm{E}-14$ & $1.97 \pm 0.29 \mathrm{E}-14$ & $2.83 \pm 0.35 \mathrm{E}-14$ & $1.99 \pm 0.29 \mathrm{E}-14$ \\
\hline Wood & $2.56 \pm 0.31 \mathrm{E}-14$ & $5.95 \pm 0.48 \mathrm{E}-14$ & $1.89 \pm 0.26 \mathrm{E}-14$ & $6.86 \pm 0.51 \mathrm{E}-14$ \\
\hline Lead & $2.57 \pm 0.34 \mathrm{E}-14$ & $1.08 \pm 0.07 \mathrm{E}-13$ & $3.08 \pm 0.38 \mathrm{E}-14$ & $8.33 \pm 0.62 \mathrm{E}-14$ \\
\hline Iron & $3.00 \pm 0.37 \mathrm{E}-14$ & $6.46 \pm 0.56 \mathrm{E}-14$ & $3.33 \pm 4.01 \mathrm{E}-14$ & $5.36 \pm 0.51 \mathrm{E}-14$ \\
\hline
\end{tabular}


Table 3. Gamma-ray FOM Detection responses

\begin{tabular}{|l|c|c|}
\hline \multirow{2}{*}{\multicolumn{1}{|c|}{ Pallets }} & \multicolumn{2}{c|}{$\begin{array}{c}\text { Gamma Detection FOM } \\
\text { For Both Detector Assemblies }\end{array}$} \\
\cline { 2 - 3 } & No DU & With DU \\
\hline Empty & $13.18 \pm 0.16$ & $31.17 \pm 0.25$ \\
\hline Celotex & $13.16 \pm 0.16$ & $33.24 \pm 0.32$ \\
\hline $\begin{array}{l}\text { Borated } \\
\text { Polyethylene }\end{array}$ & $16.03 \pm 0.22$ & $16.14 \pm 0.21$ \\
\hline Polyethylene & $12.06 \pm 0.16$ & $14.98 \pm 0.18$ \\
\hline Wood & $12.27 \pm 0.15$ & $21.14 \pm 0.21$ \\
\hline Lead & $13.56 \pm 0.17$ & $13.84 \pm 0.18$ \\
\hline Iron & $15.22 \pm 0.20$ & $14.80 \pm 0.19$ \\
\hline
\end{tabular}

inspection attention anyway, such as with radiographic imaging. Additional work is needed to

\section{Summary}

A photonuclear-based inspection technology, referred to as the PPA technology, is being developed and sponsored by the Department of Homeland Security for the detection of shielded nuclear material in air-, rail-, and maritime-cargo containers. Using a representative nuclear material (4.8-kg DU) and some well-defined shielding configurations positioned within the center of a selected cargo container inspection configuration, the PPA technology with its integrated neutron and gamma-ray detection capability did successfully detect the nuclear material whenever it was present. These results are very encouraging since it is anticipated that the detection capability will further improve when the pallets are actually loaded in their normal positions along the cargo container side, hence, effectively decreasing the DU-to-detector distances.

The neutron detection capability correctly detected the nuclear material in all pallet scenarios, except the Borated Polyethylene and Polyethylene Pallet cases, with no false positive responses. The simple gamma ray-detection capability correctly showed positive nuclear material detection in all scenarios but the Lead Pallet case when DU was present. For the latter case, detection is observed when integrating the neutron-based detection data. However, the gamma ray data did also provide false positive detections with the Borated Polyethylene and Iron Pallet cases. It should be noted that these two pallet cases are representative of very significant neutron attenuation/absorbing scenarios that should probably justify some additional better characterize the simple gamma-ray detection system, to develop detection responses for offbeam- axis locations, and to characterize multiple "calibration" pallet loading configurations.

\section{Acknowledgments}

The authors' want to thank Dr. Calvin Moss from the Los Alamos National Laboratory for his technical collaborative support of this work.

\section{References}

[1] J.L. Jones, et. al., "Photofission-based, Nuclear Material Detection: Technology Demonstration," INL Report 0201406, December 2002.

[2] J.L. Jones, et. al., "Pulsed Photonuclear Assessment (PPA) Technique: CY04 Year-end Progress Report," INL Report 05-02583, February 2005.

[3] J.L. Jones, et. al., "Pulsed Photoneutron Interrogation: The GNT Demonstration System," INL/WINCO Report 941225, October 1994. 